\title{
A MANIFESTAÇÃO DO PODER CONSTITUINTE E OS LIMITES JURÍDICOS DO PODER REFORMADOR
}

\author{
MARCUS ViNíCIUS FILGUEIRAS JÚNIOR*
}

\begin{abstract}
1 - Introdução. 2 - Fundamentos à compreensão de Poder Reformador. 3 - Alguns fundamentos doutrinários. 3.1 - Sieyès. 3.2 - Vanossi. 3.3 - Rosah Russomano. 3.4 - Manoel Gonçalves Ferreira Filho. 3.5 Nelson Saldanha. 3.6 - Celso Antônio Bandeira de Mello. 3.7 - Mario Bertolissi e Ruggero Meneghelli. 4-A manifestação do Poder Constituinte. 5 - Os limites jurídicos do Poder Reformador.
\end{abstract}

\section{1 - Introdução}

O ponto nuclear deste breve estudo é verificar se o Poder Constituinte manifesta-se quando o Poder Reformador é exercido. A justificativa da escolha deste objeto de reflexão repousa em evidentes lacunas na produção científica jurídica sobre o assunto. Revendo a doutrina trazida a público nos últimos anos, constatamos que a questão tem sido menosprezada por estudiosos e operadores do Direito; por outro lado, em debates com colegas, ouvimos com frequiência que se trata de problema atinente à área da Ciência Política e, por isso, não prioritário para a pesquisa jurídica, ou ainda que a discussão é meramente acadêmica, com pouca repercussão na aplicação do direito.

Porém, de pronto, assinalamos a natureza eminentemente jurídica do problema em tela, acrescentando que todo problema jurídico tem reflexos na prática, pois tendo o direito caráter instrumental, sempre visa incidir sobre os fatos intersubjetivos, para regulá-los. Essas premissas dão suporte à tese de que estamos em face de problema que deve ser solucionado pela metodologia jurídica.

Ademais, parece não haver dúvida da relevância de responder à questão ora proposta, para que possamos compreender os limites de uma reforma constitucional. Em outras palavras, o estudo poderá proporcionar subsídios à verificação de duas

* Advogado. Professor do Curso de Direito da Universidade Estácio de Sá. Mestrando em direito administrativo pela PUC/SP.

R. Dir. Adm.,

Rio de Janeiro, 228: 195-208,

Abr./Jun. 2002 
possibilidades, assim formuladas: se o Poder Constituinte permanecer latente e manifestar-se no Poder Reformador, do ponto de vista jurídico, estaria plenamente justificada a liberdade de realizar qualquer tipo de alteração no texto constitucional, durante o processo de reforma. Entretanto, admitida a hipótese de que o Poder Constituinte não se manifesta no Poder Reformador, torna-se forçoso compreender que há limites à liberdade para promover as aludidas mudanças.

A verdade é que o tema é complexo, pois requer a compreensão prévia de um conceito de direito, que constitui premissa filosófico-jurídica que, por seu turno. demanda investigação acerca do problema existencial do ordenamento jurídico, tema afeto à teoria geral do direito.

Não obstante tenhamos compreensão da abrangência da pesquisa, no presente ensaio, procuraremos enfrentar o assunto de modo menos ambicioso e mais objetivo, focalizando apenas seu ponto culminante.

\section{2 - Fundamentos à compreensão de Poder Reformador}

Em primeiro lugar, é preciso levar em consideração que, nos termos do seu art. 60 e parágrafos de nossa Lei Maior, o Poder Reformador define-se como a possibilidade de alterar a forma e o conteúdo da Carta Magna, por meio das Emendas Constitucionais.

Esse aspecto é objeto de reflexão de Celso Ribeiro Bastos, que presta importantes esclarecimentos, ao lecionar que a reforma normal (...) se dá na conformidade do processo previsto na Constituição e, por isso, apresenta uma continuidade ou desdobramento natural da vida jurídica do Estado" 1

Sob esse enfoque, a reforma constitui espaço para promover alterações permitidas pelo próprio sistema jurídico positivo pré-existente. É pertinente acrescentar que alguns autores costumam denominar o Poder Reformador como Poder Constituinte Derivado ou Instituído, sob o argumento de que tal poder foi, em última análise, criado a partir da concepção originária da Constituição.

Todavia, para evitar equívocos, cumpre assinalar que, ao tratar do Poder Reformador, não estaremos contemplando as iniciativas empreendidas pela via da revisão, do ponto de vista do direito positivo brasileiro, tal como previsto pelo art. $3^{\circ}$, dos Atos das Disposições Constitucionais Transitórias. Isso porque, salvo melhor juízo, a revisão é um tipo particular de reforma, com maior alcance. No caso brasileiro, foi levada a efeito no ano de 1994, produzindo as Emendas Constitucionais de Revisão de números 1 a 6 . Da mesma forma, ficam excluídas do espectro do presente trabalho iniciativas tais como o plebiscito realizado em 1993, sobre a forma e o sistema de governo, nos termos do art. $2^{\circ}$, dos Atos das Disposições Constitucionais Transitórias. 
Na presente seção, procuramos buscar respaldo no exame realizado por conhecidos doutrinadores, que se debruçaram sobre o assunto. Entendemos que essa análise poderá ser elemento valioso para fundamentar a busca de respostas consistentes para a questão norteadora do estudo.

\section{1 - Sieyès}

Sieyès ${ }^{2}$, um dos primeiros doutrinadores a dissecar a matéria, entendeu que o Poder Constituinte não desaparece, pois permanece latente, para ser utilizado, sempre que o povo desejar alterar a ordem jurídico-política do Estado. Além disso, sustentou que, quando se reforma uma Constituição, é o Poder Constituinte que, de fato, se expressa, ainda que sob forma de delegação. Admitida essa hipótese, aceita-se, por via de conseqüência, que os constituintes, quando da elaboração da Carta Magna, delegaram poderes aos legisladores para que se manifestassem em seu nome, sempre que fosse necessário alterá-la.

Para que se compreenda melhor esse posicionamento, cumpre esclarecer que Sieyès era um jusnaturalista, o que, em parte, explica a tese que defende. Vejamos: um dos direitos naturais fundamentais é a liberdade. Segundo esse enfoque, a liberdade não se esgota no ato livre. Por isso, o fundamento do poder constituinte - a liberdade de autodeterminar-se - não se exaure no exercício desse poder. Ao contrário: permanece vivo, latente, em estado de potência, disposto a converter-se em ato, a qualquer tempo, em obediência à vontade de seus titulares.

\section{2 - Vanossi}

Vanossi ${ }^{3}$, em interpretação semelhante à de Sieyès, sustentou que o poder de reformar constitui um Poder Constituinte Derivado ou "extraordinário". É interessante ressaltar que o mencionado estudioso identificou marcantes diferenças entre o conceito de Poder Constituinte Originário e Derivado. Conforme sua compreensão, aquele é fundacional, inicial, ilimitado e amplo, sendo uma potência; enquanto o Derivado constitui competência, derivada da ordem legal ${ }^{4}$.

Inobstante essa diferença, sustenta que, quando a reforma Constitucional implica na redistribuição das competências do Estado, é verdadeiramente o Poder Constituinte que se manifesta. Diante desse entendimento, podemos inferir que, para o referido doutrinador, mesmo sendo competência, o Poder Reformador constitui uma forma de expressão do Poder Constituinte, manifestando-se quando se processam reformas constitucionais.

2 SIEYÈS. Qu'est-ce que le tiers Ètat? Genève, Droz, 1970.

3 VANOSSI, Jorge Reinaldo. Entrevista publicada na Revista de Direito Constitucional e Ciência Política. Rio: Forense, 1983, p. 11/25

4 Idem. Ibidem, p. 15. 
Por fim. vale esclarecer que Vanossi, muito embora entenda o direito natural como ideologia ${ }^{5}$, aceita a idéia de que o Poder Constituinte Originário tem limites sociais, admitindo, de certa forma, a sua heteronomia. Para fundamentar sua tese, cita exemplos como da Alemanha, Itália e Japão no pós-guerra, quando precisaram submeter-se a condiçōes impostas pelos vencedores. ${ }^{6}$

\section{3 - Rosah Russomano}

Rosah Russomano, ao comentar acerca da natureza do Poder Constituinte. de início sugeriu estar de acordo com a doutrina segundo a qual esse Poder é um Poder de direito e não de fato". Segundo palavras textuais do autor, mesmo "não se condicionando a um estatuto juridico anterior, é, não obstante, um poder de direito" 8 E não deixou sombra de dúvida a esse respeito, quando acrescentou: $O$ direito não é apenas direito quando se traduz em termos positivos. Anteriormente a essa etapa, sublinhada pela positividade, em todo agrupamento humano há uma idéia sobre o que seja direito. ${ }^{9}$.

O pensamento deste ilustre jurista também revela um fundamento jusnaturalista, já que acredita na existência de direito suprapositivo. Contudo, em momento posterior do mesmo estudo ele nos surpreende, ao sustentar que o Poder Derivado é subordinado e condicionado, ao passo que o Poder Constituinte é autônomo e incondicionado. ${ }^{10}$

Decorre daí parecer admissível a inferência de que, muito embora o autor admita a existência de um direito suprapositivo, anterior ao positivo, não o considera como vinculante, capaz de condicionar a atuação dos cidadãos, já que afirmou ser o Poder Constituinte autônomo e incondicionado. Somente o Direito Positivo é que tem tal regime.

Diante do exposto, em última análise, é possível supor que esse estudioso admita a existência de dois Direitos distintos: um que vincula os seus destinatários (o positivo) e outro que não tem esse efeito (o superior ao direito positivo) ${ }^{11}$.

5 Idem. Ibidem, p. 19.

6 Idem. Ibidem, p. 16.

7 RUSSOMANO, Rosah. Curso de direito constitucional. Rio: Freitas Bastos. 4. ${ }^{a}$ ed., p. 45, 1984.

8 RUSSOMANO, Rosah. Op. cit. p. 45.

9 Idem, ibidem.

10 RUSSOMANO, Rosah. Op. cit. pp. 49 e 51.

11 Respeitosamente, entendemos insustentável a idéia de um Direito que não tenha força obrigatória, que não ofereça garantia aos seus destinatários. Um Direito que não tem o poder de ordenar, de modo heterônomo, é um perfeito não-Direito. Exatamente por isso não reconhecemos a importância, para efeito de uma análise estritamente jurídica, da discussão acerca da distinção entre o Poder Constituinte material e o formal, segundo a qual o primeiro representa uma idéia de Direito implícita na sociedade; idéia que ainda não tomou forma jurídica (Poder Constituinte formal). Os condicionamentos materiais (políticos, sociais, econômicos e culturais) são rigorosamente pré-jurídicos ou extra-jurídicos. Além do mais, em matéria jurídica, concordamos com Carlos Cossio para quem as fontes jurídicas materiais não podem ser separadas das formais. Toda forma veicula 
Tomando por base que o Direito é um fenômeno que comunica ordens, a serem obedecidas de maneira objetiva e obrigatória por seus destinatários, para alcançar a estabilização das relações sociais; concluímos que, na percepção de Russomano, os dois poderes são, de fato, distintos: enquanto o Poder Constituinte é ilimitado (portanto sem condicionante jurídica verdadeiramente obrigatória), o Poder Derivado (ou de Reforma) está vinculado à ordem jurídica vigente. Ora, se está vinculado ao sistema jurídico vigente, não poderá o Poder Constituinte interferir ou manifestar-se quando do exercício do Poder Reformador, por absoluta incompatibilidade.

Por isso, parece evidente que, segundo a concepção de Russomano, o Poder Constituinte não se manifesta quando do exercício do Poder Reformador.

\section{4 - Manoel Gonçalves Ferreira Filho}

Este ilustre jurista, docente da Universidade de São Paulo, leciona que o Poder Constituinte Instituído - o Reformador - subsiste ao longo da história, guardando, portanto, a característica da permanência.

Tal como Sieyès, entende que a Constituição é expressão viva da liberdade, que não se esgota no ato em si. Segundo suas palavras: $O$ Poder Constituinte sobrevive após a edição de uma Constituição, como expressão da liberdade humana ${ }^{12}$. Ele pauta suas conclusões no art. 28 da Declaração dos Direitos do Homem e do Cidadão, editada como preâmbulo da Constituição francesa de $1793 .{ }^{13}$

Todavia, a permanência do Poder Constituinte, segundo o autor, não significa que funcione durante o processo de reformas, vez que se restringe à criação de outra Constituição. Esse posicionamento parece claro, quando refletimos sobre a seguinte formulação deste ilustre jurista: um povo decide-se por uma Constituição, o que não significa que ele não possa, amanhã, mudar de Constituição, estabelecer uma outra Constituição." 14 (grifos nossos)

Nossa interpretação acerca do pensamento do autor adquire solidez, quando meditamos sobre outra passagem de sua obra, especificamente quando descreve as características do Poder Reformador, por ele denominado de Poder Constituinte Instituído. Ele ensina que o Poder Constituinte Instituído tem característica de derivação, subordinação e condicionamento, assumindo linha de pensamento coerente com as teses de Russomano, anteriormente expostas neste trabalho.

inevitavelmente um conteúdo. $E$, por outro lado, um conteúdo social sem uma forma normativa descaracteriza o fenômeno jurídico. $O$ direito é composto de fato, valor e também de norma, tal como assinala o normativismo concreto de Miguel Reale.

12 FERREIRA FILHO, Manoel Gonçalves. O poder constituinte. S.Paulo: Saraiva. 3. ${ }^{2}$ ed. p. 58, 1999.

13 "Um povo tem, sempre, o direito de rever, de reformar e de mudar a sua Constituição. Uma geração não pode sujeitar a suas leis a gerações futuras." (sic)

14 FERREIRA FILHO, Manoel Gonçalves. Op. cit. p. 59. 
Ferreira Filho, por certo, bem distingue os Poderes em exame; porém, demonstrando franca tendência jusnaturalista. rejeita a idéia de extinção do Poder Constituinte, após a edição da Constituição.

Em princípio, sua interpretação relativa à do Poder Constituinte não compromete a juridicidade do Poder Reformador. Todavia, ao meditarmos sobre seu entendimento acerca da vulnerabilidade das cláusulas pétreas. quando admite as suas modificações mediante alteração do art. 60 da CF — como veremos mais adiante - não se pode ter a mesma certeza...

\section{5 - Nelson Saldanha}

Nelson Saldanha ${ }^{15}$ leciona que o Poder Reformador é um poder cirúrgico, anexo ao constituinte, que foi colocado na Constituição para evitar a volta de atuação do Poder Constituinte.

No pensamento de Saldanha, percebemos clara separação entre os poderes Reformador e Constituinte. Sua doutrina esclarece que o comando normativo oriundo da Constituição que dispõe sobre o poder de reformar exige que não se confundam os institutos. O simples fato de haver previsão constitucional acerca da reforma constitui indicador de que as alterações da Constituição têm regime jurídico próprio, bem diferente da plena liberdade conferida aos constituintes.

Numa perspectiva dogmático-jurídica, tal posicionamento nos parece acertado, pois enquanto a fonte do Poder Constituinte é metajurídica, a raiz do Poder Reformador é jurídica. Por dedução, inferimos que, para Saldanha, o Poder Constituinte não se manifesta no Poder Reformador, eis que possui natureza distinta do deste.

\section{6 - Celso Antônio Bandeira de Mello}

Celso Antônio Bandeira de Mello ${ }^{16}$ sustenta, também numa perspectiva dogmático-jurídica, que o Poder Constituinte não se confunde com o Poder Reformador, também chamado de derivado. Sobretudo a partir da $11^{\text {a }}$ edição do seu "Curso de Direito Administrativo", deixa claro que não existe o Poder Constituinte derivado. O Poder Reformador não se reveste de poder para constituir nova era jurídica, independente da anterior (criar uma nova Constituição). Logo, não se confunde com o Poder Constituinte.

É forçoso reconhecer que, diferentemente do Poder Constituinte, o Poder Reformador detém limitações jurídico-positivas de ordem material, procedimental e circunstancial, como bem leciona Michel Temer ${ }^{17}$. Em assim sendo, perdeu a carac-

15 SALDANHA, Nelson. O poder constituinte. S.Paulo: RT, 1986.

16 Notas taquigráficas de seminário promovido pelo Instituto de Direito Constitucional realizado no Auditório Pedroso Horta da Câmara Municipal de São Paulo, em 29 de setembro de 1983. oportunidade em que o prof. Celso Antônio Bandeira de Mello foi o relator, tendo como debatedores Michel Temer, Edgar Silveira Bueno, Lúcia Valle Figueiredo. José Afonso da Silva e Antônio José da Costa.

17 TEMER, Michel. Elementos de direito constitucional. S.Paulo: Malheiros. 
terística principal ou essencial do poder de constituir, qual seja a liberdade de autodeterminar-se.

Em síntese, Celso Antônio leciona que o Poder Constituinte é um fato sem qualquer condicionante jurídica, enquanto o Poder Reformador tem natureza jurídica. A bem da verdade, cumpre acrescentar que Celso Antônio entende haver condicionantes político-sociais ao Poder Constituinte que, a toda evidência, não são autorizantes $^{18}$, pois não têm juridicidade para proporcionar a garantia e a necessária força vinculante.

Com relação à problemática específica da permanência do Poder Constituinte, o mestre Bandeira de Mello, em razão da racionalidade exposta, defende que o Poder Constituinte desaparece após o seu exercício, precisamente após o ato de criação da Constituição. Considerando esse pressuposto, não há espaço para imaginar-se sua manifestação, quando do exercício do Poder Reformador.

\section{7 - Mario Bertolissi e Ruggero Meneghelli}

No que se refere à permanência do Poder Constituinte, logo após o cumprimento de sua função de criar a Constituição, Bertolissi e Meneghelli demonstram pontos de vista diferentes, a partir de dois pressupostos: o normativístico e o institucionalístico ${ }^{19}$.

Com base nesses fundamentos, os autores lecionam que, do ponto de vista normativístico: (..) o poder constituinte atribuído à Assembléia constituinte seria exaurido com a promulgação da Constituição da República Italiana (...) e que, em conseqüência disso, não seria possível introduzir uma nova Constituição senão extra ordinem, 20 .

Sob a visão institucionalística, não se poderia aceitar a idéia de nova Constituição mediante elementos extra ordinem, visto que, segundo esse enfoque, o direito positivo vai além de mero reconhecimento da autoridade competente que impôs o

18 Característica essencial de uma norma jurídica que lhe dá a nota diferenciadora da norma moral, segundo nos ensina Goffredo Telles Júnior, in Iniciação à ciência do direito. S.Paulo: Saraiva, p. 43, 2001.

19 É de notar que os autores procedem desse modo na quase totalidade da obra, sempre polarizando o fundamento normativístico com o institucionalístico. As abordagens são sempre muito claras e produtivas, sobretudo, as relativas ao conceito de direito, à teoria das fontes, ao conceito de ordenamento jurídico. Pontualizamos apenas que não nos inserimos nem numa visão nem noutra. Colocamo-nos francamente a favor do normativismo, de base kelseniana, mas de conteúdo culturalista, o que, de certo modo, quebra a rigidez dogmático-normativística de Kelsen, cuja metodologia se opõe a qualquer tipo de conteudismo. Acreditamos que uma dogmática moderna não pode abrir mão do sistema normativo, mas com a consciência de que o ato de interpretar envolve inevitavelmente o trabalho com valores, que são objetos que repousam no plano axiológico.

20 BERTOLISSI, Mario e MENEGHELLI, Ruggero. Lezioni di diritto pubblico generale. Torino: G. Giappichelli editore, p. 169, 1996. Texto original: "() il potere costituente attribuito all'Assemblea costituente si sarebbe esaurito con la promulgazione della Costituzione della Repubblica italiana (...) e che, in conseguenza di ciò, non sarebbe possible introdurre una nuova Costituzione se non extra ordinem." 
ordenamento. $\mathrm{O}$ institucionalismo pauta-se na legitimidade da autoridade, aferida no plano histórico institucional. Por isso, segundo esse último enfoque, instituir uma nova Constituição implica, nada mais, nada menos, que atender aos reclamos sociais historicamente consolidados.

Decorre dessa premissa que a possibilidade de reforma da Constituição poderá encontrar limites jurídicos materiais (cláusulas pétreas), se analisado sob o ponto de vista normativístico. Todavia, "se se parte do ponto de vista institucionalístico as normas constitucionais são, portanto, todas, sem exclusão de nenhuma, revisionáveis." 21

Do exposto, concluímos que os autores entendem que uma reforma pode chegar ao ponto de constituir uma nova Constituição, sendo considerado um Poder Constituinte Institucionalizado.

\section{4 - A manifestação do Poder Constituinte}

Tomando como referência o posicionamento dos ilustres doutrinadores expostos em painel, nas seções anteriores, humildemente, ressaltamos nossa concordância com as teses de Celso Antônio Bandeira de Mello e Nelson Saldanha.

Admitindo os argumentos desses estudiosos, entendemos que o Poder Constituinte desaparece no momento em que realiza a sua obra: a Constituição. Afinal, essa é a sua função, que, exaurida, não permite que se cogite de sua permanência para reger qualquer processo reformista. Note-se que a matriz jurídica da sociedade passou a radicar na nova Constituição.

Além do mais, não podemos confundir o criador, que é o constituinte e o seu respectivo poder; com a criatura, a Constituição, que é o produto da criação. A criatura tem vida e espírito próprios, independente do seu criador. Como elucidou Engish:

O autor desempenhou o seu papel, agora desaparece e apaga-se por detrás de sua obra. A obra é o texto da lei, 'a vontade da lei tornada palavra', o 'possível e efetivo conteúdo de pensamento das palavras da lei'." (...)

"Novos fenómenos técnicos, económicos, sociais, políticos, culturais e morais têm de ser juridicamente apreciados com base nas normas juridicamente preexistentes. Ao ser o Direito obrigado a assumir posição em face de fenómenos e situações que o legislador histórico de maneira nenhuma poderia ter conhecido ou pensado, ele cresce para além de si mesmo." ( $(\mathrm{sic})^{22}$

21 BERTOLISSI, Mario e MENEGHELLI, Ruggero. Op. cit. p. 173. Texto original: “ Se si parte da un punto di vista istituzionalistico le norme costituzionali sono, quindi, tutte, nessuna esclusa, revisionabili."

22 ENGISH, Karl. Introduçāo ao pensamento jurídico. Lisboa: Fundação Calouste Gulbenkian, p. 172/173, 1996. 
A análise de Engish é particularmente interessante na medida em que assinala o dinamismo sócio-cultural e econômico, como elemento norteador do trabalho do legislador. Nessa linha argumentativa, com muita propriedade chama atenção para o fato de que um texto normativo carrega em seu bojo os valores dominantes em seu tempo. Esses valores, produto da cultura humana e de suas complexas redes de interação, são cambiantes. Por isso, a insistência em resgatar o constituinte com o seu amplo poder, fazendo-o presente na reforma da Constituição, implicará a negação de uma das características mais marcantes do direito: a sua historicidade.

Ora, se as normas jurídicas agasalham valores universais, mas não cristalizados, eis que se transformam com a evolução da história humana, é admissível que, eventualmente, venham a afastar-se de elementos materiais e imateriais, situados no âmbito dos padrões de cultura originais, que inspiraram o legislador constituinte. Decorre daí que as motivações do Constituinte, por certo, guardem alguma distância das razões que fundamentam a iniciativa dos parlamentares encarregados da refor ma.

Por isso, ao separarmos o constituinte e a sua obra - a Constituição estaremos mantendo coerência com o princípio de que nossa Lei Maior é animada por espírito próprio, conjugado com o seu tempo. Os constituintes só poderão reaparecer para instaurar nova era jurídica, isto é, criar uma nova Constituição, processo que, por sua natureza, deve guardar respeito a outros requisitos.

Ainda nessa linha de pensamento, cumpre refletir sobre a essência e existência da Carta Magna. Sob esse ângulo de visão, a rigor, o Poder Constituinte faz-se presente com exclusividade, apenas na fase da afirmação originária da Lei Maior, caracterizada por condicionantes políticos e não jurídicos, como esclareceu o mestre Celso Antônio. Por esse motivo, não faz sentido imaginar a manifestação do Poder Constituinte, para o exercício de função que já detém o seu regime traçado pelo direito vigente. Na reforma, o momento é outro, quando se faz evidente a necessidade de cognição do direito em sua essência ${ }^{23}$, mediante a sua fonte, que, no caso sob exame, é o texto constitucional.

Assim compreendido o processo e respectivas fases e características, adquire relevo a interpretação de que os Poderes Constituinte e Reformador manifestam-se em períodos distintos da vida institucional, respectivamente: o nascimento e a reforma. ${ }^{24}$

Em verdade, não podemos confundir o problema existencial da Constituição com o de sua essência, que é obtida mediante um processo de cognição, posterior à sua existência. Aliás, a esse respeito, encontramos preciosa lição do mestre FrancisPaul Bènoit, quando afirma: (...) em matéria jurídica, a existência precede a essência, ou se preferir, que, qualquer que seja os conceitos abstratos que atuam sobre os

23 Esta expressão está sendo utilizada no sentido de "conceito jurídico". Queremos dizer que ao jurista cabe construir conceitos jurídicos a partir das suas fontes.

24 VIAMONTE, Carlos Sanchez, El poder constituyente. Buenos Aires: Ed. Bbliográfica Argentina, pp. 575-577, 1957, In BULOS, Uadi Lamêgo. Elaboração e reforma das Constituições. RDA - Revista de Direito Administrativo 203: 75-106, 1996. 
criadores do direito, ninguém, no momento em que se cria uma instituição, pode pretender saber o que será, nem mesmo o que é. ${ }^{25}$

Por razão de coerência, vale recordar as lições de Karl Engish, quando elucida acerca do critério hermenêutico objetivo, que busca identificar a mens legis e não a mens legislatoris; e recorre à tempestade de Shakespeare, para esclarecer que o texto ganha vida própria na voz do intérprete, o que, para o nosso caso, resulta em mais uma razão para nos libertarmos do legislador constituinte, e então nos submetermos à sua obra: a Constituição. Segundo estas as palavras textuais do doutrinador referido ao transcrever trecho da obra de Shakespeare:

Diz Gonzalo: 'vós haveis falado mais acertadamente do que estava na vossa intenção' ao que Sebastian responde: 'E vós havei-lo entendido mais inteligentemente do que eu o pensei'." 26

No mesmo diapasão, trazemos à consideração a relação entre a capacidade latente de autodeterminação e o Poder Constituinte (potência $x$ ato). Nesse aspecto de particular interesse, cumpre ressaltar que a faculdade de agir livremente no sentido de autodeterminar-se a qualquer tempo é inerente ao homem, como sustentam jusnaturalistas do quilate de Sieyès e Ferreira Filho. Porém, essa assertiva não contradiz a tese de que o Poder Constituinte desaparece tão logo seja a nova Constituição criada.

De fato, é permanente e latente essa condição humana. Todavia, essa capacidade não poderá configurar o Poder Constituinte, pois a pura potência nada realiza, não altera a realidade jurídica, não produz efeitos concretos. A potência, no caso em exame, encontra-se em instância subjetiva.

Por isso, afirmarmos que só se pode falar na existência do Poder Constituinte quando é exercido, transformando-se em ato e possibilitando a construção de nova Constituição, que inaugurará nova era jurídica. Para tanto, faz-se necessária a instalação de uma Assembléia Constituinte.

\section{5 - Os limites juridicos do Poder Reformador}

No que concerne aos marcos delimitadores jurídicos positivos do Poder Reformador, no Brasil, a doutrina reconhece limites formais e materiais ao Poder Reformador.

Na categoria dos formais, adquire ênfase o conjunto de procedimentos exigidos, tal como previstos nos incisos I, II, III e $\S 2^{\circ}$ do art. 60 , da Constituição vigente. Por seu turno, o elenco dos limites materiais divide-se em explícitos ou implícitos. Os explícitos referem-se ao conteúdo, ao tema, estabelecidos claramente no $\S 4^{\circ}$, do

25 BÈNOIT, Francis-Paul. Le droit administratif Français. Dalloz, p. 38, 1968. Texto original: “(...) en matiere juridique, l'existence précède l'essence, ou, si lon préfêre, que, quelle que soit l'influence des concepts abstraits qui agissent sur le créateurs du droit, nul, au moment où se crée une isntituition ne peut prétendre savoir ce que'lle sera, ni même parfois ce que'lle est."

26 ENGISH, Karl. Op. cit., p. 166. 
art. 60, da CF e os implícitos dizem respeito à impossibilidade de alteração da titularidade do poder constituinte; à impossibilidade alteração do dispositivo que garante a inalterabilidade do núcleo da Constituição e, por fim, a necessidade da elaboração dos dispositivos-objeto da reforma, em harmonia com todo o sistema, de modo a garantirem a unidade da Constituição, sem inconsistências.

Cumpre analisar inicialmente o fenômeno em estudo segundo a perspectiva dos limites jurídicos materiais à reforma, comumente denominados pela doutrina de cláusulas pétreas. Não obstante os argumentos já expostos, que alicerçam o entendimento da impossibilidade de manifestação do Poder Constituinte no Poder Reformador, a questão se torna pacífica, quando dedicamos atenção ao $\S 4^{\circ}$, do art. 60 , da Constituição Federal vigente.

$\mathrm{O}$ referido dispositivo constitucional estabelece, explicitamente, limitações à alteração da Constituição. Nessa linha de análise, não será sequer objeto de deliberação as Emendas que forem tendentes a abolir a forma federativa de Estado (inc. I); o voto direto, secreto, universal e periódico (inc. II); a separação dos poderes (inc. III); e os direitos e garantias individuais (inc. IV).

Independentemente da análise do conteúdo dos referidos dispositivos constitucionais, é de se ratificar que qualquer espécie de limitação jurídica é incompatível com o Poder Constituinte, dada a plena liberdade que nele subsiste para criar uma nova era jurídica, totalmente independente da anterior. Conclui-se, pois que não poderia o Poder Constituinte manifestar-se através de um Poder que se mostra positiva e explicitamente limitado.

Mas, ao analisarmos o mencionado $\S 4^{\circ}$ e seus incisos, verificamos que protege o princípio federativo (I), o republicano (II), o sistema tripartite de distribuição de competências (III), e os direitos individuais (IV). Esse plexo de princípios representa a estrutura básica do Estado e os seus principais efeitos gerados junto aos cidadãos.

Ora, se o constituinte quis colocar a salvo tal estrutura é porque pretendeu conservar um núcleo que representa a essência da nova era jurídica criada a partir da Assembléia Constituinte. Por isso, criou mecanismos que vetam a alteração da Constituição que possa comprometer o referido núcleo.

Essa lógica nos parece acertada, pois não faria sentido instituir uma Assembléia Constituinte, se ao próprio legislador das Emendas fosse permitida a alteração substancial da Constituição ${ }^{27}$. O Poder Constituinte, pelo contrário, parte do pressuposto de que nada deve ser conservado do regime anterior no aspecto jurídico. $O$ seu exercício implica a criação de um novo núcleo jurídico, que será o fundamento de validade da nova época constitucional.

Diante dos argumentos expostos, parece não restar dúvida de que o Poder Reformador detém tão-somente a prerrogativa de alterar a forma da Constituição,

27 Uadi Lamêgo Bulos ensina que "É engano se pensar que os depositários do limitado poder de reformas, investidos na laboriosa tarefa a Lex legum, a fim de adaptá-la a novas realidades fáticas tudo podem fazer. Se assim fosse, estariam aptos para exercer o poder constituinte originário, o que lhes permitiria elaborar uma nova Constituição, e não simplesmente alterá-la." . (Op. cit. p. 95). 
mediante as regras que ela mesma estabeleceu, mantendo intacta a sua substância ${ }^{28}$. Essa substância foi criada pelos constituintes, sendo somente os representantes investidos desse poder os legitimados para criar outra Constituição.

Pensar diversamente equivale a promover o legislador ordinário - autor da reforma - a legislador constituinte. Ou, noutras palavras, implicaria a necessidade de alterar a titularidade do Poder Constituinte, que, a rigor, é um limite jurídico implícito. Portanto, a reforma não poderá significar a modificação da identidade da Constituição, sob pena de configurar uma verdadeira re-constituição, vedada pelo Direito.

Numa outra direção, focalizamos o tema sob o ângulo dos limites jurídicos implícitos, no que se refere especificamente à inalterabilidade do art. 60, CF. Sobre o assunto, cabe recordar que, se o Constituinte desejou proteger a sua obra, gravando um cerne imodificável ${ }^{29}$, é porque pretendeu indicar, como assinalamos anteriormente, que o texto normativo que criou tem uma identidade que o caracteriza, enquanto existir. Trata-se das denominadas cláusulas pétreas. Somente outra Constituição poderá desconsiderar essas cláusulas.

O cumprimento dessa garantia está abrigado no art. 60 , de maneira a não restar dúvidas acerca do perímetro do cerne constitucional, a ser protegido. Por isso, o art. 60 revela-se inalterável, vez que compõe o plexo de dispositivos que se destinam a garantir a continuidade da essência da obra do constituinte. Note-se que alterar preceito que postula a inalterabilidade de outro é alterar essoutro; porque torna possivel o que era impossível orça por alterar. ${ }^{30}$

Ferreira Filho ${ }^{31}$ sustenta ser possível a alteração das cláusulas pétreas, bastando alterar $o$ art. 60 , que as instituiu ${ }^{32}$. Ele argumenta que o dispositivo foi instituído por um Poder Constituinte derivado ${ }^{33}$.

28 Entendemos que manter intacta a substância da Constituição implica em respeitar os limites impostos às Emendas Constitucionais pelo $\S 4^{\circ}$, do art. 60 do texto Constitucional Federal, tal como sustentamos acima.

29 PONTES DE MIRANDA, Francisco Cavalcante. Comentários à constituição dos Estados Unidos do Brasil de 1934. T 2, p. 535. Apud BULOS, Uadi L. Op. cit. p. 98.

30 Idem, ibidem.

31 FEREIRA FILHO, Manoel Gonçalves. Op. cit. p. 180.

32 Em artigo publicado pela Revista de Direito Administrativo, RDA n. 202 (das páginas 11 à 17), de 1995, intitulado Significação e alcance das "cláusulas pétreas", o Prof. Manoel Gonçalves Ferreira Filho é ainda mais enfático na defesa da alterabilidade das cláusulas pétreas. Essas são as suas palavras: É freqüente, no Brasil contemporâneo, toda vez que se encara uma proposta de reforma constitucional, levantar-se o "veto" das "cláusulas pétreas". Aceitando-se a posição de alguns, o direito constitucional brasileiro estaria, quase por inteiro, "petrificado" em razão das referidas cláusulas que enuncia o $\S 4^{\circ}$ da Lei Magna vigente. Conseqüência lógica disto seria a necessidade de uma "revolução" (no sentido de quebra da ordem jurídica em vigor) para a maior parte das mudanças que a experiência e o evolver dos tempos mostrarem necessárias para o país. (...) Mas essas proibições - as "cláusulas pétreas", como se usa dizer - não têm o peso e o sentido que elas querem dar certos juristas. Elas não "petrificam" o direito constitucional positivo e por meio dele o ordenamento jurídico do país.

33 O referido autor afirma que a Constituição de 1988 foi obra do Poder Constituinte derivado e não do originário. Este seria somente aquele que criou a primeira Constituição. 
Salvo melhor juízo, o criador da Constituição de 1988 não se submeteu a qualquer limite jurídico; restou livre, no aspecto jurídico, para dispor sobre todas as matérias, como é da natureza da liberdade própria do Poder Constituinte.

Sem dúvida, a CF vigente iniciou nova era jurídica, independente da anterior; por tal motivo, sua obra revelou-se no poder de autodeterminar-se e de construir nova matriz jurídica para a sociedade brasileira. Como analisamos em momento anterior deste estudo, o pensamento deste autor se justifica em face de sua visão inegavelmente jusnaturalista, que aceita como sendo jurídicas as condicionantes sociais e políticas que exerceram influência para a elaboração constitucional.

Esse entendimento demonstra, por via de conseqüência, que os limites jurídicos impostos ao Poder Reformador poderão ser transpostos, notadamente com a supressão do art. 60, o que proporcionará a liberdade de criação/alteração verificada no Poder Constituinte. Porém, esse ponto da doutrina de Ferreira Filho acaba por levá-lo, em certa parte, a negar ou tornar ineficaz a característica de subordinação e de limitação o Poder Reformador, por ele mesmo apontada em sua obra. ${ }^{34}$

Cabe ainda contemplar o fenômeno dos limites jurídicos implícitos da reforma no tocante a teoria do ordenamento jurídico ${ }^{35}$. Nessa linha de pensamento, não alterar a identidade da Constituição implica no fato de que não só será proibida a alteração de determinados dispositivos, como já apontamos, mas também que aqueles dispositivos constitucionais que forem alterados por ocasião da reforma devem, em sua nova formulação, respeitar os demais já existentes, tornando-os compatíveis entre si, de maneira que possam formar um todo harmonioso, capaz de ser reconhecido como um sistema unitário, sem inconsistências.

Essa condição - a do sistema exigir unidade e coerência - é, a rigor, condição de existência do ordenamento. Vale dizer, um sistema de direito positivo não subsiste sem unidade e sem coerência. É ponto pacífico a inadmissibilidade de duas ordens contrárias, dentro de um mesmo sistema de normas. Em outras palavras: ou o direito permite ou então proíbe uma dada conduta. Não se pode aceitar a possibilidade lógica de, ao mesmo tempo, permitir e proibir a mesma conduta. ${ }^{36}$ Quando isso acontece, identificamos um fundamento de validade para cada comando em conflito.

Além disso, não se pode aceitar outro fundamento de validade para o nosso ordenamento jurídico, que não a Constituição Federal. $O$ fato é que a persistência das incoerências inviabiliza a existência do ordenamento.

Como elemento conclusivo, reafirmamos o pressuposto lógico de que o Poder Reformador depende da existência de uma Constituição, para que haja alteração formal, sem o comprometimento de sua identidade e substância. Qualquer alteração

34 FEREIRA FILHO, Manoel Gonçalves. O poder constituinte. p. 112.

35 Referimo-nos à teoria do ordenamento jurídico elaborada pelo jurista italiano Norberto Bobbio, amplamente aceita na comunidade jurídica científica, exposta em sua obra Teoria do ordenamento jurídico, trad. Maria Celeste Cordeiro Leite dos Santos. Brasília: Polis e UnB, 1991.

36 Permitir essa inconsistência viola o princípio lógico da identidade, que, a nosso ver, tem perfil axiomático 
jurídica deve obedecer ao que essa mesma Constituição estabelece, o que remete o raciocínio para os limites jurídicos estabelecidos para a reforma.

São por essas razões que a constatação da existência de limites jurídicos à reforma reporta-nos, compulsoriamente, ao papel político do jurista e do aplicador do direito no Brasil, qual seja o de exercer atenta vigilância sobre o processo reformador, que vem, mediante produção alucinante de emendas, comprometendo, de modo velado, a identidade da obra do Constituinte de 1988.

O Poder de Reforma não se traduz na prerrogativa de recriação da Constituição, tal como ocorre com o Poder Constituinte, sob pena de descaracterizá-lo, enquanto reforma.

Em face de todo o exposto, particularmente em face dos cristalinos argumentos doutrinários apresentados, julgamos suficientemente alicerçada a conclusão de que o Poder Constituinte não se manifesta através do Poder Reformador.

\section{Bibliografia}

BANDEIRA DE MELLO, Celso Antônio. Notas taquigráficas de seminário promovido pelo Instituto de Direito Constitucional realizado no Auditório Pedroso Horta da Câmara Municipal de São Paulo, em 29 de setembro de 1983, oportunidade em que o prof. Celso Antônio Bandeira de Mello foi o relator, tendo como debatedores Michel Temer, Edgar Silveira Bueno, Lúcia Valle Figueiredo, José Afonso da Silva e Antônio José da Costa.

BASTOS, Celso Ribeiro. Curso de direito constitucional. 20 ed., S.Paulo: Saraiva, 1999.

BÈNOIT, Francis-Paul. Le droit administratif Français. Dalloz, 1968.

BERTOLISSI, Mario e MENEGHELLI, Ruggero. Lezioni di diritto pubblico generale. Torino: G. Giappichelli editore, 1996.

BULOS, Uadi Lamêgo. Elaboração e reforma das Constituições. RDA - Revista de Direito Administartivo 203: 75-106, 1996

ENGISH, Karl. Introdução ao pensamento jurídico. Coimbra: Fundação Kalouste Goubenkian.

FERREIRA FILHO, Manoel Gonçalves. $O$ poder constituinte. 3.ed., S Paulo: Saraiva, 1999.

RUSSOMANO, Rosah. Curso de direito constitucional. 4.ed., Rio de Janeiro: Freitas Bastos, 1984.

SALDANHA, Nelson. O poder constituinte. S.Paulo: RT, 1986.

SIEYĖS. Qu'est-ce que le tiers Ėtat? Genève, Droz, 1970.

TEMER, Michel. Elementos de direito constitucional. S.Paulo: Malheiros, 1999.

VANOSSI, Jorge Reinaldo. Entrevista publicada na Revista de Direito Constitucional e Ciência Política. Rio: Forense, 1983. p. 11/25. 